\title{
Increasing Complexity and Limits of Organization in the Microlithography Industry:
}

\section{Implications for Japanese Science-based Industries}

by

Hiroyuki Chuma**

December 2004

Forthcoming Working Paper

Research Institute of Economy, Trade and Industry (RIETI)

**Hiroyuki Chuma is Professor at the Institute of Innovation Research, Hitotsubashi University, 2-1, Naka, Kunitachi, Tokyo 186-8603, Japan (e-mail: ce00005@srv.cc.hit-u.ac.jp); and Faculty Fellow at RIETI (Research Institute of Economy, Trade and Industry). 


\section{Increasing Complexity and Limits of Organization in the Microlithography Industry: Implications for Japanese Science-based Industries}

Hiroyuki Chuma

Institute of Innovation Research,

Hitotsubashi University

\section{Introduction}

There is an interesting paper (Helper, 2000) that advocates the importance of inductive thinking to economists with a bias for deductive thinking by saying that "You can observe a lot just by watching." Unfortunately, it has been virtually impossible to experience the delightfulness of manufacturing without some comprehension of the production systems per se. This is particularly true in science-based industries. ${ }^{1}$ Take the case of highly automated state-of-the-art semiconductor factories (or fabs). No matter how close an observer, clad in dust-proof suit, may stand to observe various production processes, that person will have no clue as to what is taking place unless he or she has some basic understanding of the tasks being done at molecular and atomic levels. This failure to understand applies not only to people ignorant in science but also to quite a few technicians, engineers, and scientists, although there may be some differences in degree.

Under this general climate, scientific and technological innovations have constantly been taking place in various fields at such astonishing rates that it has become indispensable for people to maintain specialized knowledge at advanced levels and to integrate this specialized knowledge on a large scale, dispersed over finely divided disciplines. This requirement stems primarily from frequent incidents of complex phenomena that are hard to reproduce. In addition, this situation has been made more complex over the years by two factors: the globalization of various markets, due to rapid advancements in transportation and communication systems, and consumers' diversified and upgraded

\footnotetext{
${ }^{1}$ An industry is called science-based if the time lags between scientific discoveries and their industrial applications are very short. Pharmaceutical, biotechnology, semiconductor, and fine chemical industries and the like fall into this category (see Goto and Odagiri, 2003).
} 
preferences brought on by affluence. In reality, as Adam Smith predicted, the breadths and depths of markets are being broadened so that both markets and organizations are becoming more and more specialized and differentiated (Langlois, 2003; Lamoreaux, Raff and Temin, 2002).

As the level of complexity surpasses a certain threshold, the limitations of relying on a handful of individuals with both specialized and integrated knowledge are suddenly exposed. This is because their capacities for information processing ("brain power") hit physico-chemical limits. Once these individuals reach their limits, full-scale organizational management over a wide range of related areas becomes indispensable in order to harness the information-processing capabilities of the right people in the right places. Furthermore, the range that requires full-scale management is not limited to the various divisions within a corporation; it extends beyond corporate boundaries permanently (Chesbrough, 2003).

The necessity for reaching beyond borders is particularly high in science-based industries in which the speed of innovation, or the "clockspeed" (Fine, 1998), is extremely rapid. In such a situation, we need to apply the "organization determines strategy" approach advocated by Roberts (2004) rather than the "strategy determines organization" approach recommended by Chandler (1962). This is because the optimal strategy could only be found inexpensively and quickly in an organization where both the rapidly changing circumstances and the appropriate knowledge are seen at a glance and are effectively shared with considerable certainty by the people involved across the hierarchy. Furthermore, the more efficiently the organization can turn the feedback loop of "organization $\rightarrow$ strategy $\rightarrow$ organization $\rightarrow$ strategy $\rightarrow$..., the more quickly it can search for preferable strategies.

In order to construct an organization that can respond to such a high clockspeed, it is not sufficient for the people involved to pursue their specialized and integrated knowledge in stand-alone mode. Rather, this knowledge has to be autonomously shared and networked through informationprocessing capabilities to handle organizational complexities holistically. It is crucial, in other words, to create an organization where autonomous collaboration among the people involved could encourage 
“emergence"” or self-assembly effects (Johnson and Broms, 2000).

Creating such an "emergent" or self-assembling organization is not a simple task. Indeed, unless the appropriate mechanism design is adopted, the "limit of organization" appears at various hierarchical layers, causing coordination failures in which local optimization does not lead to global optimization. This happens because the more autonomous the people or groups involved become, the more conflicts of interest occur. Furthermore, the more advanced and complex an organization is, the more seriously it tends to induce vexing problems such as "failure to recognize the extent of externalities," "lack of intrinsic motivation to recognize them," and "failure in communication to cope with them."

The purpose of this paper is threefold: to identify characteristics of the complexities and organizational limits that science-based industries in Japan are facing, to clarify the causes and effects of those characteristics and to show how they are related to the recent decline in global competitiveness in these industries. The microlithography industry is used for this purpose as a typical example of science-based industries.

There are four primary reasons for choosing the microlithography industry. (1) Microlithography is often regarded as an ultimate precision tool in human history with "integral architecture" (Fujimoto, 2001) ${ }^{4}$ and represents the quintessence of the latest scientific and technological knowledge. (2) Nikon and Canon, two of the most representative Japanese manufacturers, held insurmountable global competitiveness in this industry over the two decades beginning in the mid 1980s. (3) Such competitiveness has been eroding, however, since the emergence of ASML in the Netherlands in the late 1990s. (4) The decline in this industry goes against the

\footnotetext{
2 "Emergence" means that the aggregate exceeds the sums of individual capabilities within a system.

3 "Limit of organization" here means the limit of organizational capabilities to cope with increasing complexities of technology and market in the sense that individual (local) optimization within an organization does not lead to global maximization.

${ }^{4}$ Product architecture is called "integral" when the total performance of final products needs post-assembly fine tuning because it could not be presumed even if the performance of each key component was assured.
} 
conventional wisdom that Japanese manufacturers are very good at products with integral architecture. $^{5}$

The next section of this paper provides an overview of microlithography. Section 3 describes the rise and fall of the microlithography industry based on world market-share data, the innovation speed of the state-of-the-art microlithography tools and a time-series statistical analysis. Section 4 presents a brief historical explanation of what ASML is. Sections 5 and 6 make up the main part of the paper. Section 5 initially provides the technological background for ASML's leapfrogging progress since the mid 1990s. Then it introduces the new concept of "interim modularity" vis-à-vis "ex ante modularity" à la Baldwin and Clark (2000) to explain how ASML tries to cope effectively with the drastically increasing complexity of such a technology. The concept of interim modularity is defined as the communication benefits induced by the modular architecture during trial-and-error development processes, no matter how incomplete such architecture may be. The paper emphasizes that extremely complex tools like microlithography require interim modularity to effectively orchestrate the dispersion of specialized knowledge and know-how over a wide range of professionals inside and outside of corporations. Section 6 shows that, based on evidence about ASML's ways of collaboration in $\mathrm{SPIE}^{\mathbf{6}}$ and ASML's development methods for embedded control software, interim modularity is more effectively pursued by ASML than by Nikon or Canon. Finally, Section 7 summarizes the paper and provides several implications for Japanese science-based industries.

\footnotetext{
${ }^{5}$ Nikon, Canon and ASML were the primary subjects for this paper and, due to their helpful cooperation, intensively investigated. Hitachi High Technology (formally Nissei Sangyo) was included in ASML as the distributor of ASML tools in Japan. Our field research was also done for ULTRATEC (California), which is the sole U.S. microlithography manufacturer. Afterward, the range of field research was expanded to include domestic and foreign semiconductor chip and material manufacturers and public and private research consortiums. To be more specific, Epson, NEC (including NEC Electronics), Trecenti UMCJ, Spansion Japan (formally Fujitsu-AMD), Sony, Renesas, Hitachi, TSMC, Winbond, UMC, Elpida, Toyota (Hirose Plant), Toshiba, JSR, Tokyo Ohka Kogyou, MIRAI STARC and others were added.

${ }^{6}$ Society of Photo-Optical Instrumentation Engineers
} 


\section{Overview of Microlithography}

\subsection{Basic Structure of Microlithography}

Microlithography can be simply defined as a special copying machine that prints integrated circuit (IC) patterns in a photomask onto a (silicone) wafer through a projection lens. The basic structure is shown in Figure 1. This figure shows (a) the reticle (or photomask) stage upon which a photomask is placed, (b) the projection lens used to project reduced IC patterns in a photomask onto a wafer and (c) the wafer stage upon which a wafer is placed.

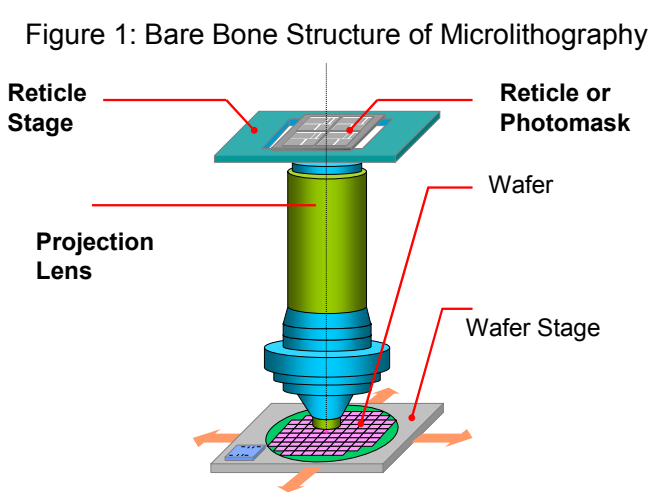

Source of data: Modified based on ASML's public presentation

Currently, there are two types of microlithography: a stepper (step and repeat) type and a scanner (step and scan) type. The former uses all of a projection lens to project and expose all the IC patterns in a photomask at once, whereas the latter uses only the best part, the "cream," of a projection lens to transfer a portion of the IC patterns in a photomask, little by little. The scanner has been developed to meet chipmakers' ever-demanding need for miniaturization due to Moore's law. ${ }^{7}$ For the scanner, only the cream of the projection lens could deliver the required optimum performance. Accordingly, while only a wafer stage is needed to move in a stepper, both reticle and wafer stages are

\footnotetext{
${ }^{7}$ The experiential law first observed by G. Moore from INTEL as an exponential growth in the number of transistors per integrated circuit (IC): the doubling of transistors every couple of years. For details, see http://www.intel.com/research/silicon/mooreslaw.htm.
} 
needed to move in a scanner, by which very precise and synchronous movements can be guaranteed.

Performance of both wafer and reticle stages is critical to total performance of scanner-type microlithography. The faster the stepping speed is, the higher the throughput. The more precisely the positioning of stages and lens can be controlled, the more significantly both resolution ${ }^{8}$ and the overlay accuracy $^{9}$ can be enhanced. To get a better-focused image on a wafer, a precise alignment unit is indispensable in attaining precise measurements, adjustments and corrections (Levinson, 2001).

\subsection{Basic Performance and Rapidly Advancing Complexity}

Basic performance of microlithography is normally expressed by three attributes: (a) resolution, (b) overlay accuracy and (c) throughput (productivity). Among them, Rayleigh's equation below is used to indicate (maximally attainable) resolution (Levinson, 2001).

(1) Resolution $=\mathrm{k}_{1} \lambda \mathrm{NA}$,

where $\mathrm{k}_{1}$ is a constant value determined by various exposure-related process conditions, $\lambda$ is a wavelength of the light source and NA (Numerical Aperture) is a kind of brightness of the projection lens. Previously, mercury lamps were commonly utilized, but now laser beams, called DUVs (Deep Ultra Violet), are in frequent use. Overlay accuracy is heavily dependent upon the metrological and controllable precision of both the stage and alignment systems. Throughput, which is measured by the number of wafers processed per hour, is heavily dependent on the feeding speed of stages and autofocusing speed of the projection lens.

Complexity of microlithography has been increasing rapidly with advancement in both hardware and software, as can be seen in Table $1 .{ }^{10}$ According to this table, the lithography tools

\footnotetext{
${ }^{8}$ The minimum line width transferred on a silicone wafer.

${ }^{9}$ Interlayer alignment precision when multiple layers of integrated circuit patterns are transferred on a silicone wafer.

${ }^{10}$ PAS5000 shown in the table is assumed to be the i-line PAS5500/50 released in 1989, based on official data available from ASML. In addition, the KrF Scanner AS5500/500 released in 1997 was the first scanner in the PAS5500 series. Twinscan was released only after late 2000.
} 
manufactured in 2000 were equipped with more than six times the number of CPUs, and approximately eight times the number of sensors and motors as the tools manufactured in 1989 . Moreover, FPGA (Filed Programmable Gate Array) was not used at all before 1990, but around 2000 tools were equipped with 500 units of FPGA. These facts indicate that hardware complexity has been increasing very rapidly over the last decade. The software complexity has also grown rapidly. One kind of software codes (Lines of Source Codes) has increased almost sixfold over the decade, while the other kind of software codes has grown by more than twenty-two times in size over five to seven years. Thus, both software and hardware complexity are becoming more and more difficult to cope with. In fact, ASML's previous president and CEO believes in "Dunn's law" associated with "Moore's law": that a software development team will double in size every four years (Dunn, 2002).

Table 1. Changes in complexity of ASML microlithography

\begin{tabular}{|c|c|c|c|c|c|c|}
\hline & $\begin{array}{l}\text { PAS5000 } \\
\text { Stepper }\end{array}$ & $\begin{array}{c}\text { PAS5500 } \\
\text { Stepper }\end{array}$ & $\begin{array}{l}\text { PAS5500 } \\
\text { Scanner }\end{array}$ & $\begin{array}{l}\text { Twinscan } \\
\text { AT: } 700 \mathrm{~S}\end{array}$ & $\begin{array}{c}\text { Twinscan } \\
\text { AT: } 1100 \mathrm{~T} \\
\end{array}$ & $\begin{array}{l}\text { Twinscan } \\
\text { (Unkonwn) }\end{array}$ \\
\hline Initial Sale & 1989 & $1996 *$ & $1997 *$ & 2000 & $2001 *$ & 2003* \\
\hline $\begin{array}{l}\text { Sampling } \\
\text { Frequency }(\mathrm{MHz})\end{array}$ & & 3.85 & 2.5 & 3.3 & 5 & \\
\hline $\begin{array}{l}\text { Processor (CPU) } \\
\text { Frequency }(\mathrm{MHz}) \\
\end{array}$ & & 40 & 60 & 60 & 350 & \\
\hline $\begin{array}{l}\text { \# Processors } \\
\text { (FPGA) }\end{array}$ & $8(0)$ & & $25(200)$ & & & $50 \quad(500)$ \\
\hline \# Axes & & 3 & 17 & 24 & 36 & \\
\hline \# Sensors & 50 & & 150 & & & 400 \\
\hline$\#$ Actuaters & 40 & & 100 & & & 300 \\
\hline \# Motion & & 3 & 6 & 10 & 14 & \\
\hline $\begin{array}{l}\text { (1)Lines of Source } \\
\text { Codes (include } \\
\text { coment lines) }\end{array}$ & 200 millions & & 900 millions & & & 1250 millios \\
\hline $\begin{array}{l}\text { (2)Lines of Source } \\
\text { Codes }\end{array}$ & & 20000 & 140000 & 260000 & 450000 & \\
\hline
\end{tabular}

Source of data: Compiled by the author from public data available from ASML and other agencies. 
Onvlee et al., (2003) and Burntink et al. (2004) have conducted a structural analysis of the embedded control software of ASML scanners. The software is reported to consist of more than ten million lines of $\mathrm{C}$ source codes. These researchers guess that 20 to 30 percent of the total source codes must be "crosscutting" in that each embedded module is not self-contained but runs risks of interdependencies over various modules, and they believe that reducing such crosscutting codes could be quite effective in further enhancing the performance of ASML scanners.

\section{Rise and Fall in the Microlithography Industry}

\subsection{Arrival of Nikon's Stepper}

The first commercial Japanese stepper was released by Nikon in 1980. This stepper is said to be the fruit of a VLSI (Very Large-scale Integration) Research Project that began in 1976 as a government-private joint project (Tarui and SEAJ, 1991). In those days, GCA (U.S.A.), which had successfully launched the first commercial stepper in the world in 1976, almost monopolized the world stepper market (VLSI, 1992). ${ }^{11}$ Nikon managed to take over the top position in the Japanese market as early as 1983. Nikon advanced without resistance since then and captured the number one global market share by 1990. At the same time (1983), Canon-- which had once conquered the world microlithography market by its fully automated proximity aligners ${ }^{12}--$ turned its attention to steppers, taking advantage of their superb in-house optical and precision machine fabrication technologies. From that time until around 1995, Nikon and Canon together held between 70and 75 percent of the global market share.

\footnotetext{
${ }^{11}$ The projection lens had been supplied by Carl Zeiss SMT of Oberkochen, Germany.

${ }^{12}$ Prior to steppers, IC patterns were transformed from masks to wafer by contact, proximity or projection printing. Proximity aligners use the proximity printing for which the mask is placed in close proximity (about $10 \mu \mathrm{m}$ ) to the wafer. For details, see Henderson and Clark (1990), Hirota (2002), Levinson (2001) or Wolf (2004). According to VLSI (1992), even in 1984, aligners occupied 39 percent of the world microlithography markets, while steppers occupied 55 percent.
} 


\subsection{Emergence of ASML}

Just as the Japanese semiconductor industry started to lose its competitiveness in the global market in the early 1990s, a dramatic change in the global microlithography market took place (see Figure 2). ASML (in the Netherlands) began to make its mark. ASML had held less than 10 percent of the global microlithography market in 1990, controlling less than Hitachi at that time. ${ }^{13}$ ASML's market share grew to 14 percent by 1995 and continued to grow to about 30 percent in 2000. By 2002 ASML was the largest microlithography manufacturer in the world, capturing more than 50 percent of the global market. ASML, on the one hand, and Nikon and Canon, on the other, have been engaged in a dead-heat race since $2002 .^{14}$

Figure 2. Changes in global microlithography market share

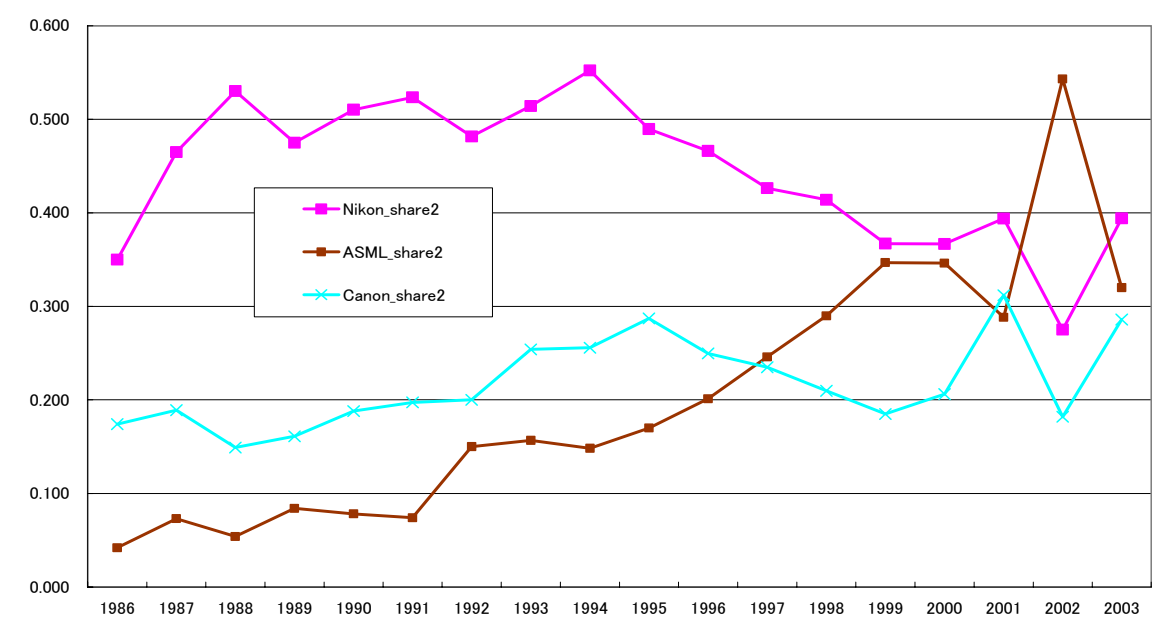

Source of data: Annual reports of the respective corporations and other public information.

The weakening competitiveness of Nikon and Canon compared with ASML can be also seen from the differences in the speed of innovation about state-of-the-art ArF scanners ${ }^{15}$ (see Table 2).

\footnotetext{
${ }^{13}$ Hitachi eventually withdrew from the market in 1994.

${ }^{14}$ ASML acquired SVGL (U.S.A.). The aggregate market share of the two companies, in fact, exceeded that of Nikon in 2000.

${ }^{15}$ Microlithography using $193 \mathrm{~nm}$ wavelength argon fluoride laser.
} 
According to this table, the speed of innovation by ASML tended to exceed that by Nikon or Canon after the resolution was enhanced beyond $0.1 \mu \mathrm{m}$.

Table 2. Comparison of launch dates for commercial ArF scanners by Nikon, Canon and ASML

\begin{tabular}{|c|c|c|c|c|c|c|c|c|c|}
\hline Year & Maker & Product Type & $\begin{array}{l}\text { Wave } \\
\text { Length }\end{array}$ & $\begin{array}{c}\text { Contractio } \\
\text { n Rate }\end{array}$ & $\begin{array}{l}\text { Field Size } \\
(\mathrm{mm})\end{array}$ & NA & $\begin{array}{c}\text { Resoluti } \\
\text { on } \\
(\mu \mathrm{m})\end{array}$ & $\begin{array}{c}\text { Wafer } \\
\text { Size } \\
(\mathrm{mm})\end{array}$ & $\begin{array}{l}\text { Throughput } \\
\text { (per hour) }\end{array}$ \\
\hline 1998 & ASML & PAS5500/900 & ArF & $1 / 4$ & $26 \times 33$ & 0.60 & 0.150 & $\phi 200$ & 40(参考) \\
\hline 1999 & ASML & PAS5500/950 & ArF & $1 / 4$ & $26 \times 33$ & 0.63 & 0.130 & $\phi 200$ & 60(参考) \\
\hline 1999 & Canon & FPA-5000AS1 & ArF & $1 / 4$ & $26 \times 33$ & 0.60 & 0.130 & $\phi 300$ & \\
\hline 2001 & Nikon & NSR-S305B & ArF & $1 / 4$ & $25 \times 33$ & 0.68 & 0.110 & $\phi 300$ & 78 \\
\hline 2001 & Canon & FPA-5000AS2 & ArF & $1 / 4$ & $26 \times 33$ & 0.70 & 0.110 & $\phi 300$ & 88 \\
\hline 2001 & ASML & PAS5500/1100 & ArF & $1 / 4$ & $26 \times 33$ & 0.75 & 0.100 & $\phi 200$ & 90 (参考) \\
\hline 2001 & ASML & TWINSCAN AT:1100B & ArF & $1 / 4$ & $26 \times 33$ & 0.75 & 0.100 & $\phi 300$ & 93 \\
\hline 2002 & Canon & FPA-5000AS3 & ArF & $1 / 4$ & $26 \times 33$ & 0.75 & 0.100 & $\phi 300$ & 105 \\
\hline 2002 & Nikon & NSR-S306C & ArF & $1 / 4$ & $25 \times 33$ & 0.78 & 0.100 & $\phi 300$ & 85 \\
\hline 2003 & ASML & TWINSCAN AT:1200B & ArF & $1 / 4$ & $26 \times 33$ & 0.85 & 0.080 & $\phi 300$ & 103 \\
\hline 2003 & Canon & FPA-6000AS4 & ArF & $1 / 4$ & $26 \times 33$ & 0.85 & 0.080 & $\phi 300$ & 140 \\
\hline 2003 & Nikon & NSR-307E & ArF & $1 / 4$ & $26 \times 33$ & 0.85 & 0.080 & $\phi 300$ & 112 \\
\hline 2004 & ASML & PAS5500/1150C & ArF & $1 / 4$ & $26 \times 33$ & 0.75 & 0.090 & $\phi 200$ & 135(参考) \\
\hline 2004 & ASML & TWINSCAN XT:1250B & ArF & $1 / 4$ & $26 \times 33$ & 0.85 & 0.065 & $\phi 300$ & 114 \\
\hline 2004 & ASML & TWINSCAN XT:1400 & ArF & $1 / 4$ & $26 \times 33$ & 0.93 & 0.065 & $\phi 300$ & 122 \\
\hline 2004 & Nikon & NSR-S308F & ArF & $1 / 4$ & $26 \times 33$ & 0.92 & 0.065 & $\phi 300$ & 140 \\
\hline
\end{tabular}

Source of data: Companies' annual reports and other publicly available documents.

\footnotetext{
${ }^{18}$ Specifically, according to Thin Film Manufacturing (2002), these were RET(resolution enhancement technology) patent (US-563821, US-6233041), scan control patent (US-5473410), stage vibration isolation reaction frame patent (US-6271640, US-6008500), and counterbalance mechanism patent (US-6255796, US-6323935).
} 
It should be noted here that, in Japan and the United States, Nikon filed suits against ASML for the infringement of seven basic Nikon patents. The technologies involved have all been applied frequently in the latest ASML microlithography tools, called TWINSCAN. ${ }^{18}$ These lawsuits were resolved in September 2004 after ASML and Zeiss (Carl Zeiss SMT AG.) agreed to pay Nikon \$147 million (US) as license fees. As is exemplified in Figure 3, Nikon still has superior element technologies, but the number of U.S. patents assigned to ASML or the ASML coalition (ASML, Zeiss and Philips) has increased significantly since the mid 1990s. ${ }^{19}$

\subsection{Is This Weakening Competitiveness Temporary?}

More than a few semiconductor-industry specialists in Japan are still quite optimistic about the technological potential of Nikon and Canon, maintaining as follows: "The decreasing world market share of Nikon or Canon has been caused not by the weakened potential competitiveness of Nikon or Canon but by one of the Japanese chipmakers that used to be the greatest user of Japanese microlithography tools. Therefore, the decrease that has occurred since the mid 1990s is likely to be temporary." The relevance of this "temporary" hypothesis will be tested in this section, based on timeseries data and using statistical analyses where the share variable of each microlithography manufacturer (ASML, Canon or Nikon) between 1986 and 2003 is regressed by various explanatory variables, as follows:

$$
\begin{aligned}
& \text { (2) } Y(t)=\alpha+\beta\left(\Delta \text { WsemiMSize }(t) \_2\right)+\gamma\left(\Delta \text { JapanSemiMSizeRatio }(t) \_2\right)+ \\
& \theta \cdot d_{-} D U V(t)+\varepsilon(t)
\end{aligned}
$$

\footnotetext{
${ }^{19}$ Based on the Delphion (www.delphion.com), where the following Boolean search was conducted: g-line or i-line or KrF or ArF or duv or "deep uv" or "deep ultra violet" or euv or "extreme uv" or "extreme ultraviolet" or "x-ray")*(projection and exposure or lithography) or multilayer*mirror). In determining these terms of search, I had a valuable advice from the executive scientist from one of the microlithography makers investigated in this paper.
} 
Figure 3. Transition in acquired U.S. patents by ASML, Canon, and Nikon

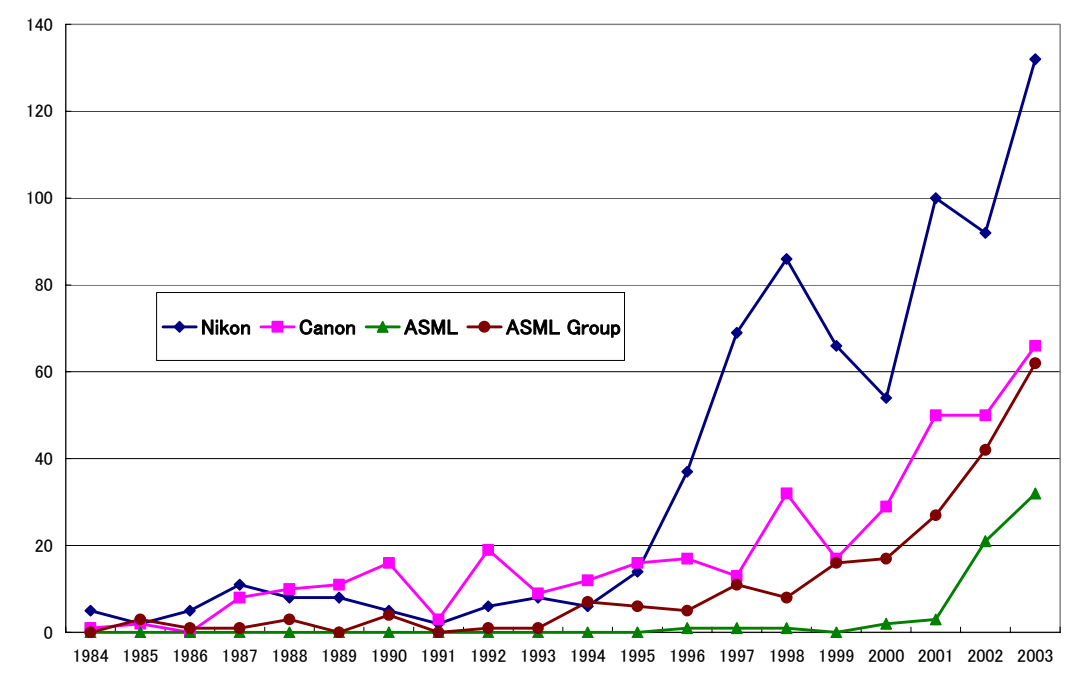

In equation (2), $Y_{i}(t)$ is the transformed share variable that takes a real number. More concretely, $Y_{i}(t)$ is defined as $\log \left(y_{i}(t) /\left(1-y_{i}(t)\right)\right)$ where $y_{i}(t)$ is the actual world microlithography share of manufacturer $i$ at period $t$. For simplicity, subscript $i$ is abbreviated in equation (2). Moreover, $\triangle W$ semiMSize $(t), \Delta \operatorname{JapanSemiMSize}(t), d_{-} D U V(t)$, or $\varepsilon(t)$ is, respectively, the rate of increase in total world semiconductor shipments (US \$), the rate of increase in the ratio of Japanese semiconductor shipments in the world (US \$), a DUV dummy variable, or an error term in period $t$. Subscript " 2 " in $\Delta W$ semiMSize(t) or $\Delta$ JapanSemiMSize(t) in equation 2 means that a two-year lag is taken for each variable. $d_{-} D U V(t)$ is defined to be unity if $t$ is greater than 1997 and zero otherwise. This is because, as is well known, the number of shipments in DUV steppers and/or scanners exceeded the number of shipments in the other types of older tools for the first time in the world in 1998. $\varepsilon(t)$ is a random variable that has a zero expected value and variance of $\sigma^{2}$. As typical time series data, $\{\varepsilon(t)\}$ is assumed to follow a first order autoregressive (AR(1)) process. Hence, a GLS (generalized least square) method is applied in the actual estimation of equation 2. 
The estimation results are shown in Table 3. The share of ASML is positively and highly significantly influenced by both $\Delta W \operatorname{semiMSize}(t) \_2$ and the DUV dummy variable, whereas the share of Nikon is negatively and highly significantly influenced by these variables. In addition, as is expected, 4 JapanSemiMSize $(t) \_2$ is positively and highly significant for Nikon but not for ASML. The results for Canon are quite different from ASML and Nikon: both $\Delta W \operatorname{semiMSize}(t) \_2$ and the DUV dummy variable are not significant. Only _JapanSemiMSize $(t) \_2$ is moderately significant for Canon.

Judging from these results, it could be surmised that the decrease in Nikon and Canon's share of the world microlithography market is partly due to the decrease in the competitiveness of the Japanese semiconductor industry itself. At the same time, however, both the increase in world semiconductor shipments and the new era of DUV tools' dominance have a significantly negative impact on Nikon's share and partly on Canon's. Accordingly, the decreasing trend for them must also be caused by other structural factors.

Table 3. Time-Series Analysis of the Transition in World Microlithography Market Share

Prais-Winsten AR(1) regression -- iterated estimates

\begin{tabular}{|c|c|c|c|c|c|c|c|c|c|}
\hline & Coef. & $t$ & $P>\mid t$ & Coef. & $t$ & $P>|t|$ & Coef. & $t$ & $P>t$ \\
\hline Company Name & \multicolumn{3}{|c|}{ ASML } & \multicolumn{3}{|c|}{ Nikon } & \multicolumn{3}{|c|}{ Canon } \\
\hline wsemi_msize_2 & 1.08 & 9.89 & 0.00 & -0.24 & -3.79 & 0.00 & 0.29 & 1.97 & 0.07 \\
\hline$\Delta$ japan_semi_ratio_2 & -3.69 & -1.68 & 0.12 & 2.71 & 2.75 & 0.02 & 3.87 & 2.16 & 0.05 \\
\hline d_duv & 0.41 & 2.45 & 0.03 & -0.36 & -4.42 & 0.00 & -0.21 & -0.95 & 0.36 \\
\hline constant & -13.74 & -11.45 & 0.00 & 2.65 & 3.67 & 0.00 & -4.53 & -2.74 & 0.02 \\
\hline rho & 0.18 & & & 0.04 & & & 0.25 & & \\
\hline $\begin{array}{l}\text { R-Squared } \\
\text { Durbin-Watson statistic }\end{array}$ & $\begin{array}{l}0.92 \\
1.81\end{array}$ & & & $\begin{array}{l}0.87 \\
1.93\end{array}$ & & & $\begin{array}{l}0.51 \\
1.78\end{array}$ & & \\
\hline
\end{tabular}

Regression with robust standard errors

\section{Legend}

wsemi_msize: World Semiconductor Shipment (by WSTS)

$\triangle$ japan_semi_ratio: Japan's Ration in wsemi_msize

subscript 2 (_2) means "2 years lagged variable of the wsemi_msize or $\Delta$ japan_semi_ratio)

d_duv $=1$ if year $>1998$ ( $=$ the year when the number of shipment of DUV tools exceeded the other) 


\section{What Is ASML?}

ASML was established by people who spun off from Philips in 1984. One can trace the roots of ASML back to the period when Philips developed its unique in-house stepper in $1973 .{ }^{20}$ Philips itself commercialized the first stepper in $1980 .{ }^{21}$ At the onset, ASML took the form of a joint venture by ASM International (established in 1968) and Philips Electronics. In the interim, ASM International could not afford to maintain a stake in ASML, which had been losing money constantly around that time, and was forced to concentrate on its main business (semiconductor thin film tools like CVD (Chemical Vapor Deposition)). Thus, ASM International sold half of the stocks it owned to Philips and the other half to a Dutch bank. Thereafter, until 1988, ASML continued to be a subsidiary of Philips. Actually Philips owned about 60 percent of all ASML stock around this period.

ASML was listed on the Amsterdam Stock Exchange and NASDAQ in 1996. Increased volume of sales to foundries ${ }^{22}$ in Taiwan like TSMC (Philips' alliance) was a primary factor in the firm's success. ${ }^{23}$ Philips had owned about 35 percent of all ASML stock when ASML went public. ${ }^{24}$ After that the ratio Philips owned steadily declined to about 27 percent in 1997, 7 percent in 2000 and less than 4 percent in 2003. Despite such a low stockholding ratio, Philips still maintains control over corporate governance of ASML. ${ }^{25}$ It is also interesting that U.S. investment companies like FRM and Capital Group International hold over 25 percent of the outstanding ASML stocks having [that have?] no voting rights.

\footnotetext{
${ }^{20}$ More concretely, the first patent (US3602591) for a step \& repeat principle in the United States was awarded to Philips in 1971 while the first one (JP53039075A2) in Japan was awarded to Hitachi in 1978.

${ }^{21}$ This was introduced by the researcher at the Philips Research Lab. in the SPIE proceedings in 1980 (see Wittekoek, 1980).

${ }^{22}$ Fabrication-specific semiconductor manufacturers.

${ }^{23}$ ASLM market share in Taiwan has been about 50 percent since the mid 1990s.

${ }^{24}$ According to U.S. SEC data, just prior to being publicly traded (in other words, in 1995), Philips sold to FRM (a U.S. investment company) by mutual consent the shares it still owned, which represented a little more than 13 percent of the outstanding shares at that time.

${ }^{25}$ This must be mainly because of the corporate governance style used by ASML, which could be implemented easily in the Netherlands. For details, see the Appendix.
} 
An examination of profiles of the current ASML board members shows them to be well qualified as highly advanced specialists in the related science, technology or marketing. Indeed, the newly appointed CEO was the former executive vice president of the TV division in Thomson, the French appliance giant. He had also occupied important positions at Intel and DELL. The preceding CEO had worked for Philips, prior to joining ASML, as a director in both the consumer electronics and semiconductor divisions. He had also served as an executive director for ARM (G.B.) and had worked as a semiconductor engineer with Motorola and General Electric. He had even served as an outside board member for ST Microelectronics. The CEO prior to him, who served from 1990 to 1999 , was a straight Philips-bred engineer. Of the four current vice presidents, two are engineers, one from Philips Semiconductor (COO) and the other from AMD. The third is a straight ASML system design engineer and the fourth is a finance specialist who worked for Detroit-Tohmatsu.

Table 4. Profile of outside board members serving ASML

\begin{tabular}{|c|c|c|c|}
\hline Position & Year & Previous Positions Held & Position co-held \\
\hline $\begin{array}{l}\text { Outside } \\
\text { Director / } \\
\text { Chairman }\end{array}$ & 1995 & $\begin{array}{l}\text { Phillips, Vice President, CEO of Consumer } \\
\text { Electronics Div. }\end{array}$ & $\begin{array}{l}\text { Outside board membership of } \\
\text { other corporations }\end{array}$ \\
\hline $\begin{array}{l}\text { Outside } \\
\text { Director }\end{array}$ & 1997 & TNO, CEO & Same a above \\
\hline $\begin{array}{l}\text { Outside } \\
\text { Director }\end{array}$ & 1996 & Carl Zeiss, Chairman \& CEO & $\begin{array}{l}\text { Max Plank Research } \\
\text { Institute, Committee member, }\end{array}$ \\
\hline Outside & 2001 & IBM Electronics, Chairman, CEO, SVLG & \\
\hline Outside & 1998 & Akzo Nobel, Vice President (Finance) & Outside board membership \\
\hline $\begin{array}{l}\text { Outside } \\
\text { Director }\end{array}$ & 2002 & $\begin{array}{l}\text { Unilever, Executive Director, General Manger of } \\
\text { Tax Dept, (specialist on tax and legal matters) }\end{array}$ & \\
\hline
\end{tabular}

SVLG — Silicone Valley Lithography Group (USA) — was acquired by ASML in 2002.

Source of data: various U.S. SEC document (F-20) 
As for their outside board members, the latest U.S. SEC document (F-20) lists the personal profiles outlined in Table 4. According to this information, all the outside board members serving ASML are among the best scientists, engineers and financial, legal and tax specialists in the world. The close alliance between ASML and Philips/Zeiss/TNO ${ }^{27}$ can be also inferred from this table.

\section{Increasing Complexity of Microlithography and the Role of Modular Architecture}

\subsection{Increasing Complexity of the Lithography Process}

When IC patterns in a photomask become extremely miniaturized, it becomes impossible for most of the diffracted light to pass through the projection lens. As a result, patterned images can no longer be focused onto a wafer. Even if the diffracted lights can manage to pass through the projection lens, with very dense IC patterns, the image projected onto the wafer would lose contrast and the boundaries between adjunct patterns could not be discerned. In order to alleviate such a problem, RET (Resolution Enhancement Technology) has been developed to exert tight control over the amplitude, phase, direction, and possibly polarization, of emitted lights in capturing more of the diffracted lights. $^{28}$

Beginning in the mid 1990s, when the demand for miniaturization in submicron order due to Moore's law started to increase drastically, RET became implemented gradually, mainly with DUV steppers at various commercial fabs of the leading semiconductor chipmakers in the world. RET is a kind of technology able to lower the value of $\mathrm{k}_{1}$ in the previous Rayleigh's equation by keeping $\lambda$ and NA constant. Figure 4 specifies how extensively RET has been implemented. According to this figure, the value of $\mathrm{k}_{1}$ started to improve from the mid $1990 \mathrm{~s}$, in contrast to its stagnation in the early $1990 \mathrm{~s}^{29}$

The introduction of RET together with DUV steppers opened a new frontier for optical

\footnotetext{
${ }^{27}$ TNO is the famous nonprofit research institution on applied sciences in the Netherlands, which is more or less a huge national technology research institute. The microlithography division at TNO is located in Eindhoven (the Netherlands), the castle town of Philips.

${ }^{28}$ Schellenberg, 2004 gives a succinct description on these methods, together with the history of the process of development of the RET.

${ }^{29}$ RET itself has a long history. For details, see Schellenberg, 2004.
} 
lithography tools. Yet, at the same time, tool manufacturers began to experience complex problems they had not confronted in the past. It became extremely difficult to ensure printing accuracy from original IC design patterns to actual patterns in a photomask and then from there to patterns projected onto a wafer (Mori and Higashiki, 2004). DUV steppers themselves could not have been introduced without accidentally having the following Three Sacred Treasures simultaneously: ${ }^{30}$ High Purity Synthetic Fused Silica Lens (only from Canon, Nikon, Zeiss group or Corning), High-energy version of $\mathrm{KrF}$ Laser (exclusively from Cymer, Komatsu, or Lambda Physik) and Chemically Amplified Resist (invented and developed by IBM). ${ }^{31}$

\section{Figure 4. Changes of value of $k_{1}$ (IBM's case)}

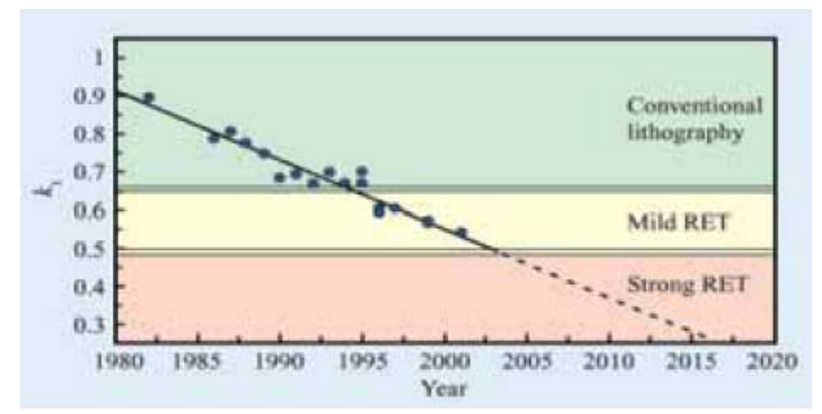

Source of data: Liebmann et al., 2001

What made the situation more complicated was the fact that finding the root causes of imprecise printing accuracy became more and more difficult. Accordingly, it became inevitable for microlithography manufacturers to collaborate with leading chipmakers as well as toolmakers (e.g., coater-developers, etchers, or resist strippers) and photomask, materials (e.g., resist, low-k or high-k materials), and EDA software manufacturers. ${ }^{33}$ In other words, as microlithography tools got closer to

\footnotetext{
${ }^{30}$ Photo-sensitive materials coated on wafers. For details, see Wolf, 2004.

${ }^{31}$ This point is emphasized in Suzuki (2003) and in the personal communication with him.

${ }^{33}$ EDA means Electronic Design Automation. For the brief and quite understandable explanation of coater-developer, etchers, or resist strippers, low-k or high-k materials, see Wolf, 2004.
} 
the "physico-chemical limits" (Fujimura, 2000), in order to innovate their tools effectively, these workers needed to unite their own element technologies with much wider and potentially more useful ones that existed beyond their corporate boundaries. It was at about this time that ASML made great leaps ahead.

The fact that microlithography manufacturers had been facing the "physico-chemical limits" can be seen indirectly in the transition process of NA in i-line microlithography tools. ${ }^{34}$ This is shown in Figure 5, which plots NAs of newly commercialized i-line tools by Nikon, Canon and ASML. The figure indicates that NAs tended to be increased at roughly the same pace until 1994 and, after this period, flattened out and remained at the same levels thereafter. This stagnation period coincides with the time when $\mathrm{KrF}$ steppers ${ }^{35}$ began to be dominant. Both Figure 4 and Figure 5 strongly indicate that the superior technologies of Nikon and Canon for NA enhancement markedly contributed to maintaining their absolute dominance in the late 1980 s and early $1990 \mathrm{~s}^{36}$

\subsection{Difficulties in Pursuing ex ante Modularity}

Quite a few people, including industry specialists and researchers, attribute the phenomenal success of ASML to the built-in modular architecture of ASML microlithography tools, à la Baldwin and Clarke (2000). ${ }^{37}$ To be sure, "ASML final assembly plants add less than $10 \%$ value" (George, 2002). In contrast to Nikon's or Canon's, ASML has the following features: (a) End-users can easily take out the stages for maintenance purposes. (b) The automatic calibration mechanism can fully guarantee that the stages that are removed will return to the previous position after such maintenance jobs. (c) The exchange or upgrading of the projection lens can be done with great ease on factory

\footnotetext{
${ }^{34}$ Machine using $360 \mathrm{~nm}$ wavelength mercury lamp as light source.

${ }^{35}$ Machine using krypton fluoride laser beam (248 nm wavelength) as light source.

${ }^{36}$ This is one of the reasons that GCA and Hitachi, which depended on outside sources (esp. Zeiss) for their projection lenses, eventually withdrew from the market.

${ }^{37}$ For example, see Roest and Schuurmans, 1997; George, 2002.
} 
floors of the chipmakers themselves. The question is, Are these features of ASML's modular architecture sufficient to support the aforementioned strength of ASML relative to Nikon or Canon? The answer must be, Not necessarily.

Figure 5. Changes of NA values in i-line lithography machine (Nikon, Canon and ASML)

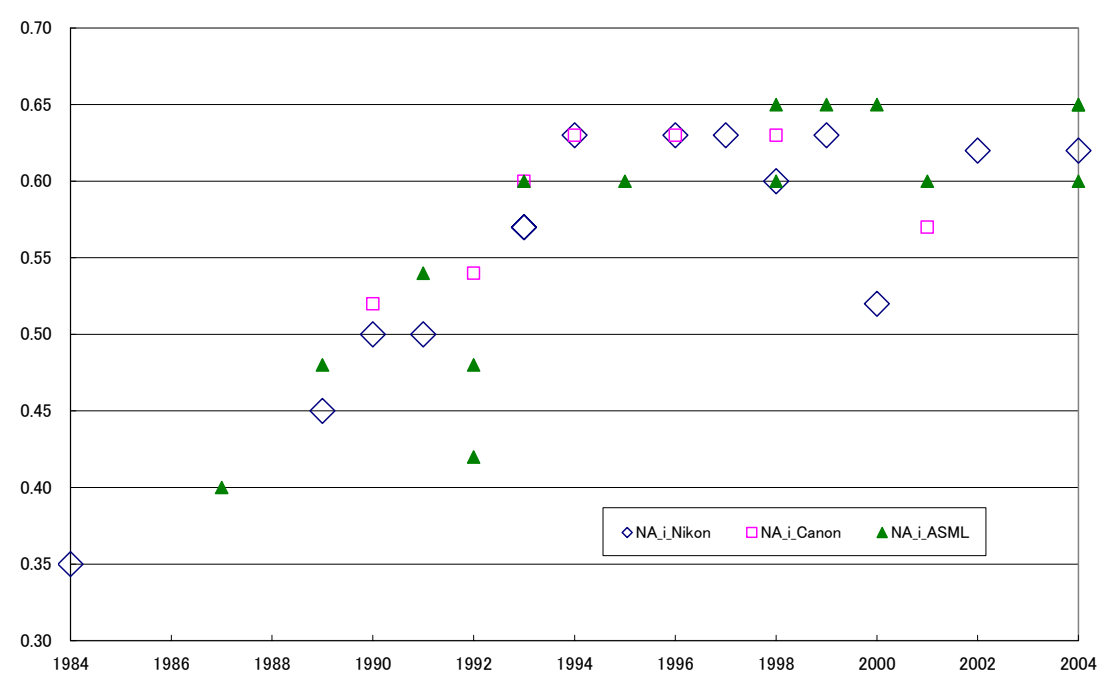

Source of data: publicly available data from respective manufacturers.

Implementing a "perfect" modular architecture in product design generally implies that the total performance of the final product specified at a system-design phase can automatically be assured as long as the performance of each key component (called "module") is individually assured. As advocated by Baldwin and Clarke (2000), such modular architecture could provide the following benefits: (a) expanding the range of complexity addressable, (b) extending the scope of addressable business risks by parallel development and production or outsourcing and (c) shortening various lead times by parallel development and production or outsourcing. In order for these benefits to be manifested, however, the modular architecture in question must be perfect. This is because the interface between key modules could be open or standardized to any companies that could 
manufacture the corresponding components only if it is perfect. This paper distinguishes the benefits induced by perfect modular architecture called ex ante modularity, from the other important benefits that will be discussed immediately, to be called interim modularity.

For tools that require ultimate performance like microlithography, it is extremely difficult to provide for ex ante modularity. This is because the tolerances of microlithography tools are much tighter than the ones for each key component. Indeed, each tool must be finally assembled and statically and dynamically fine-tuned by taking into account idiosyncrasies of the individual components in actual use. For example, despite their advanced modular architecture, ASML standard microlithography tools require (a) 4 to 10 days for final assembling, (b) another 20 to 30 days for customizing to chipmaker-specific specifications and (c) another 20 to 30 days after installation for final testing at the chipmakers' sites. Thus, the length of time required to finalize ex ante specifications is roughly nine months from the initiation of an official order to the end of final testing. These three processes, (a), (b) and (c), require for Nikon (or Canon), respectively, 6 to 10 days (or 6 to 21 days), 40 to 60 days (or 28 to 29 days) or 30 to 50 days. ${ }^{38}$

Reflecting the difficulty in attaining ex ante modularity, ASML and Philips have quite a solid relationship through mutually exclusive contracts. For example, ASML has continued frequent access to Philips' research and development (R\&D) resources in return for fees. ${ }^{39}$ Besides, Philips has granted ASML "a worldwide, irrevocable, and non-exclusive license" under which ASML can use the (microlithography-related) patents owned by Philips without any charge. The two companies are also geographically located within easy driving distance. ${ }^{40}$ In this sense, ASML and Philips can be considered to be virtually the same entity in terms of R\&D activities, as well as corporate governance.

\footnotetext{
${ }^{38}$ The requirement for one process for Canon in (c) is not available. The numbers in this context are for the year 2000. Regrettably, we cannot confirm whether or not the night shift is taken into account.

${ }^{39}$ From several US SEC documents (F-20).

${ }^{40}$ The main body of Philips is located at Eindhoven in the Netherlands, while ASML is located on a central street of the city of Veldhoven, only 20 minutes by car from Eindhoven. Philips Central Research Lab. is also located just several kilometers from ASML. Moreover, the
} 
Table 5. Extent of outsourcing at ASML

\begin{tabular}{|c|c|c|c|}
\hline Major Components & ASML & Nikon & Canon \\
\hline \multicolumn{4}{|l|}{ Projection Lens } \\
\hline $\begin{array}{r}\text { Development \& } \\
\text { Design }\end{array}$ & Zeiss & In-House & In-House \\
\hline $\begin{array}{r}\text { Desion } \\
\text { Glass Making }\end{array}$ & $\begin{array}{l}\text { Zeiss Group } \\
\text { (Hereaeus, Shott), } \\
\text { Corning, Shinetsu } \\
\text { Crystal, Ohara }\end{array}$ & $\begin{array}{l}\text { Mostly In-House, } \\
\text { Partly Ohara }\end{array}$ & $\begin{array}{l}\text { Canon Group } \\
\text { (Optron, Ohara) }\end{array}$ \\
\hline Polishing & $\begin{array}{l}\text { ASML Optics } \\
\text { (Previous US } \\
\text { Tinsley). }\end{array}$ & In-House & In-House \\
\hline Assembling & Zeiss & In-House & In-House \\
\hline Illunination System & $\begin{array}{l}\text { Zeiss(main), } \\
\text { Lambda Physics }\end{array}$ & In-House & In-House \\
\hline \multicolumn{4}{|c|}{\begin{tabular}{|l|l} 
Stage & \\
\end{tabular}} \\
\hline $\begin{array}{r}\text { Development \& } \\
\text { Design }\end{array}$ & Philips & In-House & In-House \\
\hline Assembling & Philips - Group & In-House & In-House \\
\hline \multicolumn{4}{|c|}{\begin{tabular}{|l|l|} 
Light Sources & \\
\end{tabular}} \\
\hline Marcury Lamp & Mainly Ushio & Mainly Ushio & Mainly Ushio \\
\hline DUV & $\begin{array}{l}\text { Cymer(main), } \\
\text { Lambda Physics }\end{array}$ & $\begin{array}{l}\text { Cymer(main), } \\
\text { Giga Photon }\end{array}$ & $\begin{array}{l}\text { Cymer(main), } \\
\text { Giga Photon }\end{array}$ \\
\hline $\begin{array}{l}\text { Body (Development } \\
\text { \& Fabrication) }\end{array}$ & $\begin{array}{l}\text { Philips and Philips } \\
\text { Group }\end{array}$ & $\begin{array}{l}\text { In-House and } \\
\text { Nikon Group }\end{array}$ & $\begin{array}{l}\text { In-House and } \\
\text { Canon Group }\end{array}$ \\
\hline \multicolumn{4}{|l|}{ Allignment System } \\
\hline $\begin{array}{r}\text { Development \& } \\
\text { Design }\end{array}$ & $\begin{array}{l}\text { Zeiss, Philips } \\
\text { (Partially Agilent) }\end{array}$ & In-House & In-House \\
\hline $\begin{array}{r}\text { Interferrometer, Bar } \\
\text { Mirror, etc.) }\end{array}$ & $\begin{array}{l}\text { Agilent, Zygo, etc } \\
\text { and Zeiss }\end{array}$ & Zygo etc. & Zygo etc. \\
\hline \multicolumn{4}{|l|}{ Software } \\
\hline System Design & In-House & In-House & In-House \\
\hline OS & Outside & Outside & Outside \\
\hline $\begin{array}{r}\text { Each Component } \\
\text { Software }\end{array}$ & Outside & Outside & Outside \\
\hline Tool Software & $\begin{array}{l}\text { In-House \&Zeiss or } \\
\text { Philips? }\end{array}$ & In-House & In-House \\
\hline
\end{tabular}

Sources: based on author's field research and various publicly available data

Similar facts exist in the relationship between ASML and Zeiss. In fact, ASML and Zeiss have structured their relationship as an exclusive strategic alliance in the areas of product research, design,

semiconductor department of Carl Zeiss (Carl Zeiss SMT), which supplies the projection lens unit, is only about four hours away by car.

${ }^{43}$ According to U.S. SEC document F-20, the (financial) loan to Zeiss equaled 48 percent of the total loans provided by ASML in 2001. 
planning, manufacturing and pricing, as well as customer support and warranty services. ASML also provides various loans to Zeiss. ${ }^{43}$ Among these loans is a non-interest-bearing loan that is to be repaid by Zeiss's shipments of projection lenses to ASML. ${ }^{44}$ Moreover, as in shown in Table 5, most of key components like the stages, projection lenses, illumination and alignment systems are provided exclusively by Zeiss or Philips and their related subsidiaries. Accordingly, if ASML is counted as the ASML group ASML-Philips-Zeiss, the formal organizational difference between ASML and Nikon or Canon almost disappears. Thus, it is hard to argue that ASML is using ex ante modularity processes like (b) and (c) more effectively than Nikon or Canon.

Then the question becomes, How is the advanced modular architecture embedded in ASML microlithography tools related to the phenomenal advances of ASML since the mid 1990s? The answer must be, Closely related.

\subsection{Resolving Complexity by interim Modularity}

Even confronted with complex phenomena, if one can discern a certain kind of basic structure among inextricably intertwined complexities, no matter how incomplete such a structure may be, one can avoid groping blindly in the dark and find some clue to untangling them. The more hierarchically visualized at a glance such a basic structure is, the more people start to discover the essence of those complex phenomena from the same perspective so that they can deeply understanding them. This is because such a basic structure can markedly increase the visibility of complex phenomena and because it serves as an effective communication tool among the people involved. In other words, Zuboffian "power of (information) panopticon" can be experienced. ${ }^{45}$

In this paper, we consider the power of panopticon to be another important benefit induced by ASML's modular architecture. Such a power can be expected, no matter how incomplete the

\footnotetext{
${ }^{44}$ From several U.S. SEC documents (F-20).

${ }^{45}$ See Zuboff, 1988.
} 
corresponding modular architecture is. In fact, the more intertwined the corresponding complexities are, the more strongly such an incomplete modular architecture can arouse such a power. In this paper, we call this kind of power of panopticon induced by modular architecture interim modularity. ${ }^{46}$

In contrast to this interim modularity, ex ante modularity à la Baldwin and Clarke could be expected only if the corresponding modular architecture were almost perfect in that the total performance of final products specified at a system-design phase could automatically be assured as long as the performance of each key component were individually assured. Accordingly, ex ante modularity tends to be expected for mature technologies, such as IBM PCs. In the case of microlithography tools, however, which perpetually have to be dependent on highly advanced and undeveloped technologies, one cannot expect ex ante modularity. Such extremely complex tools require interim modularity as communication benefits to effectively orchestrate specialized knowledge and know-how dispersed over a wide range of professionals beyond corporate boundaries.

\subsection{Fujimoto's Architecture Theory and interim Modularity}

According to Fujimoto (2001), product architecture can be classified in terms of "modular vs. integral architecture" and "open vs. closed architecture." Modular architecture refers to the perfect modular architecture described in this paper, while integral architecture presupposes that the total performance of the final product needs post-assembly finetuning because it cannot be automatically guaranteed even if the performance of each key component is assured. Open architecture aims to standardize interfaces between final products and their related key components industrywide, while

\footnotetext{
${ }^{46}$ The concept of ex post modularity has quite a resemblance to the benefits of "protocols" proposed by Csete and Doyle (2002). They maintain that "If modules are ingredients, parts, components, subsystems, and players, then protocols describe the corresponding recipes, architectures, rules, interfaces, etiquettes, and codes of conduct. Protocols here are rules that prescribe allowed interfaces between modules, permitting system functions that could not be achieved by isolated modules. Protocols also facilitate the addition of new protocols and organizations into collections of mutually supportive protocol suites. Like modules, they simplify modeling and abstraction, and as such may often be largely 'in the eye of the beholder.' A good protocol is one that supplies both robustness and evolvability."
} 
closed architecture aims to makes them proprietary for each manufacturer.

After providing these definitions, Fujimoto maintains that, compared to their U.S. counterparts, Japanese manufacturers tend to be more competitive in products with integral and closed architecture and less competitive in products with modular and open architecture. To borrow Fujimoto's terminology, "Japan is good at integration while United States is good at combination." According to Fujimoto's definitions, microlithography tools are characterized by extremely integral and closed architecture. Nikon and Canon, however, have been facing really tough times with this kind of product. Thus, it appears that Fujimoto's proposition needs to be modified and extended from a little different aspect. We believe that the interim modularity concept can afford an important clue to such a seemingly inexplicable phenomenon.

Although Fujimoto's idea is insightful, it appears to be inadequate for understanding the characteristics of microlithography tools full of highly advanced complexity. In particular, it must be necessary to distinguish between the role of architecture embodied in finally commercialized products and the architecture working as a communication tool during trial-and-error processes used to search for the appropriate architectures or "protocols" in targeted finally commercialized products. Microlithography tools are characterized by extremely closed and integrated architecture when looked at as finally commercialized products. As was confirmed before, this is definitely true even for ASML's tools. When looked at during architecture-searching processes, however, closed interfaces are apt to be stumbling blocks in seeking wisdom dispersed over a wide range of professionals inside and outside companies.

Accelerating wisdom-seeking speed desperately needs an efficient way of communicating among a wide range of professionals. To accomplish this, depending on interim modularity induced by modular architecture becomes inescapable, no matter how incomplete such architecture might be at an initial phase. The more efficiently such communication can be achieved, the more quickly the relevant architecture can be discovered and embodied in the corresponding finally commercialized products. 
The final architecture must undoubtedly be closed and integral, whereas the architecture utilized for searching must definitely be open to all the people involved, beyond corporate boundaries and (incompletely) modular.

\section{Interim Modularity: Backbone of ASML's Competitiveness}

\subsection{R \& D Collaboration à la ASML with IMEC ${ }^{47}$}

Unlike Nikon or Canon, ASML is involved only in system design and final assembly while depending on outside institutions like Zeiss, Philips and IMEC for R\&D and parts assembling. So, how could ASML gain R\&D capabilities that even surpass Nikon or Canon? Are there any prominent differences in R\&D activities?

One of the distinct differences between Nikon and Canon, on the one hand, and ASML, on the other, is that ASML has a long-standing close relationship with IMEC, as well as with Philips and Zeiss. In fact, most of ASML's microlithography prototypes (called $\beta$ tools) were first installed at IMEC. Examples are the first generation KrF stepper in 1989, the second generation $\mathrm{KrF}$ scanner in 1995, the first generation ArF scanner in 1999 and the first generation F2 scanner in 2004. ${ }^{48}$ ASML and IMEC have also frequently exchanged personnel of various ranks. Furthermore, in the late 1990s, IMEC and Philips entered into a strategic R\&D agreement. Consequently many researchers from Philips Research Laboratory have recently engaged in R\&D activities at IMEC. ${ }^{49}$

In IMEC there are several ongoing semiconductor-related projects (called IIAP: IMEC Industrial Affiliation Program) on which researchers from various chip, tool and material

\footnotetext{
${ }^{47}$ IMEC (Interuniversity Micro Electronics Center), located in Leuven, Belgium, is said be the best European (and perhaps in the world) semiconductor process technology research institute. It was spun off from Leuven Catholic University in 1983.

${ }^{48}$ F2 scanners use an F2 eximer laser of 157nm wave length. This information comes from the author's interview with the chief executive in charge of IMEC microlithography and the 1995 IMEC annual report. For further information on IMEC, please refer to the July 2004 issue of Densi-Zairyo ("Materials for Electronics" in English: one of the prestigious Japanese trade journal).

${ }^{49}$ From IMEC 1999 annual report.
} 
manufacturers participate. ASML $\beta$ tools play key roles in these projects. Take, for example, the 193nm Optical Lithography project, which commenced in 1999. For this project, IMEC (1 researcher), ASML (7 researchers), resist manufacturers (five companies: 17 researchers), a coater-developer manufacturer (2 researchers), chipmakers (five companies: 13 researchers) and a photomask inspection and adjustment manufacturer ( 2 researchers) were involved. ${ }^{50}$ Among the chipmakers, such world-leading corporations as Intel, Infinion, Micron and Texas Instruments were included. The same goes for the tool and material manufacturers.

As mentioned earlier, since the introduction of the full-scale implementation of RET, in order to increase the speed of innovation for microlithography tools, microlithography manufacturers must always have close collaborations with chip, tool and material manufacturers. ASML has very effective opportunities to brush up their $\beta$ tools through such close collaboration in various IIAPs at IMEC. It is also quite beneficial to the chip, tool and material manufacturers participating in the IIAPs to have relatively inexpensive and easy access to ASML $\beta$ tools. Resist manufacturers, for example, can use such $\beta$ tools to test their particular resist while it is under development. Moreover, if they want, they can privately retain their test results by exclusively using ASML's $\beta$ tools for themselves. Results of some tests conducted by competitors are also made available via neutral IMEC coordinators within IIAPs; these results are quite useful for each participant as bench-mark data. The feedback from specific chipmakers can also be obtained, perhaps resulting in a bilateral contract between specific resist and chip manufacturers. In some cases, the resist produced by a specific manufacturer is recommended by the IMEC, leading to new markets. ${ }^{51}$

In distinct contrast to ASML, neither Nikon nor Canon has a place for resonance like IMEC. While it is not rare for Nikon or Canon to enter into bilateral strategic collaboration with specific chip, tool or material manufactures, these opportunities are quite limited in scope in comparison to what

\footnotetext{
${ }^{50}$ From IMEC 1999 annual report.

${ }^{51}$ All of these facts are based on the author's interviews of a resist manufacturer that participates in various IIAPs.
} 
ASML has enjoyed at IMEC. To be sure, there have been seemingly IMEC-like R\&D consortiums, such as ASET, ${ }^{52}$ MIRAI, ${ }^{53}$ STARC,${ }^{54}$ SELETE $^{55}$ and ASPLA, ${ }^{56}$ in Japan, but none of them, has succeeded in reaching the efficiency level attained at IMEC, mainly because of their inefficient organizational design and IP protection mechanism. ${ }^{57}$

Figure 6. Changes in paper submission format by ASML-Philips-Zeiss to SPIE Conferences

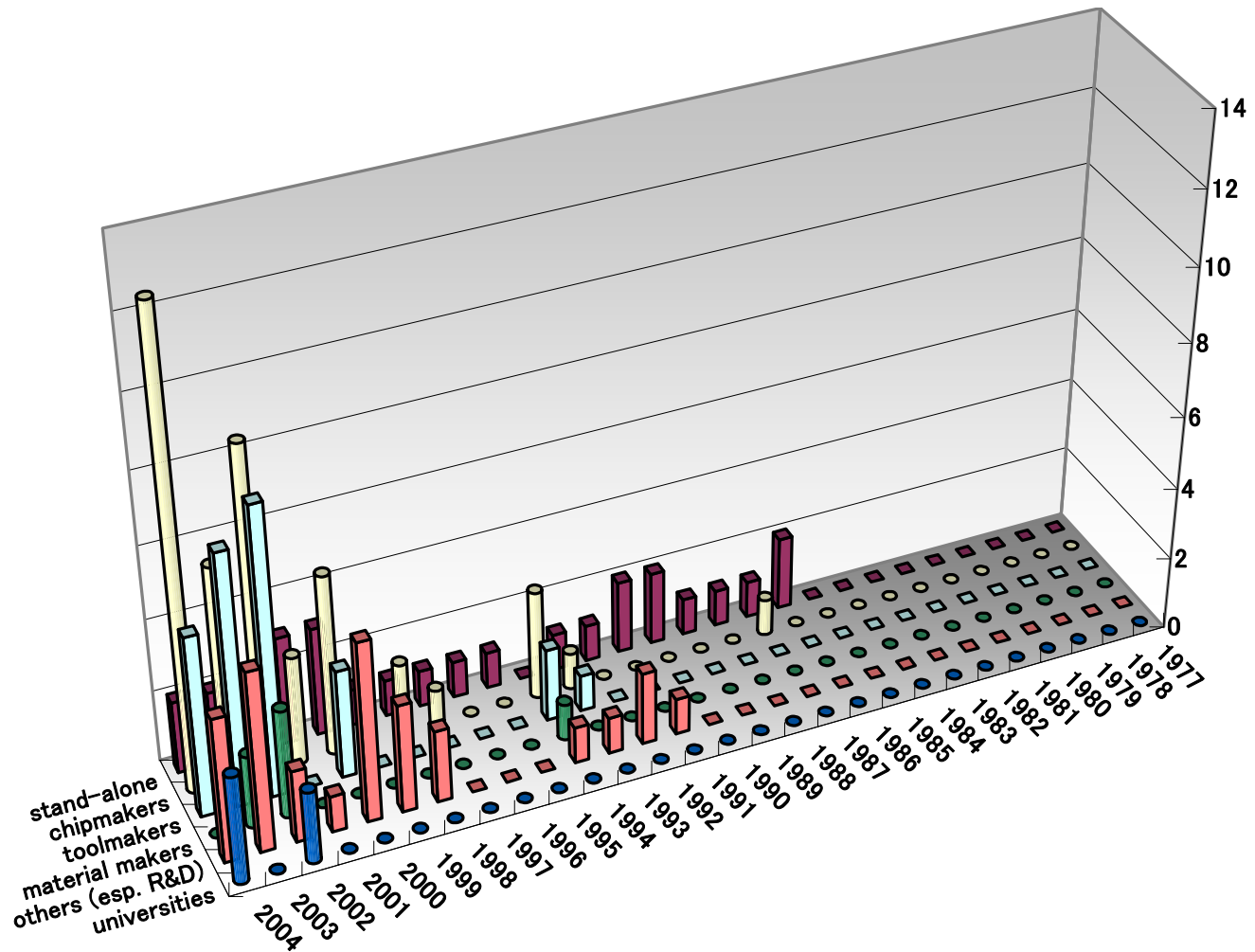

\footnotetext{
${ }^{52}$ Association of Super-Advanced Electronics Technology.

${ }^{53}$ Millennium Research for Advanced Information Technology.

${ }^{54}$ Semiconductor Technology Academic Research Center.

${ }^{55}$ Semiconductor Leading Edge Technology, Inc.

${ }^{56}$ Advanced SOC Platform Corporation.

${ }^{57}$ Information comes from interviews conducted by the author. For details, also see Kohzu and Chuma, 2004.
} 


\subsection{R \& D Collaboration through SPIE}

ASML's awareness of the importance of interim modularity, more than Nikon's or Canon's, is reflected in the manner in which it uses SPIE conferences as another place for resonance. SPIE, which is one of the most prestigious scientific societies about microlithography in the world, has held a conference once a year for more than three decades. At this conference, microlithography manufacturers, lithographers and scientists from world-leading chipmakers have presented papers. The number of chipmaker presenters is generally much larger than the number of microlithography manufacturers. Lithographers and scientists from material manufacturers, EDA vendors, universities, or other research institutions have also presented papers or participated in this conference.

Figure 7. Changes in paper submission format by Nikon to SPIE Conferences

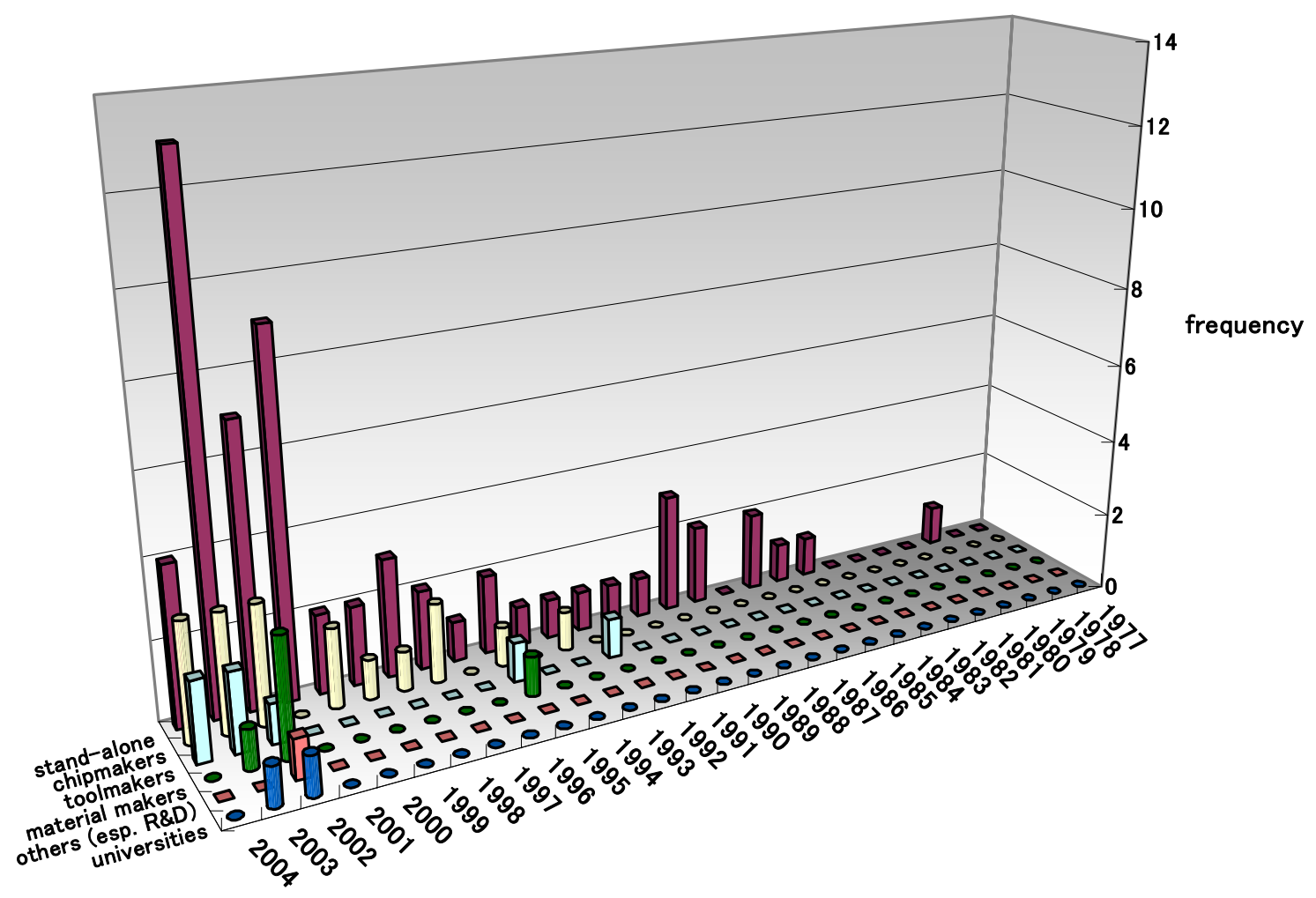


Figure 8. Changes in paper submission format by Canon to SPIE Conferences

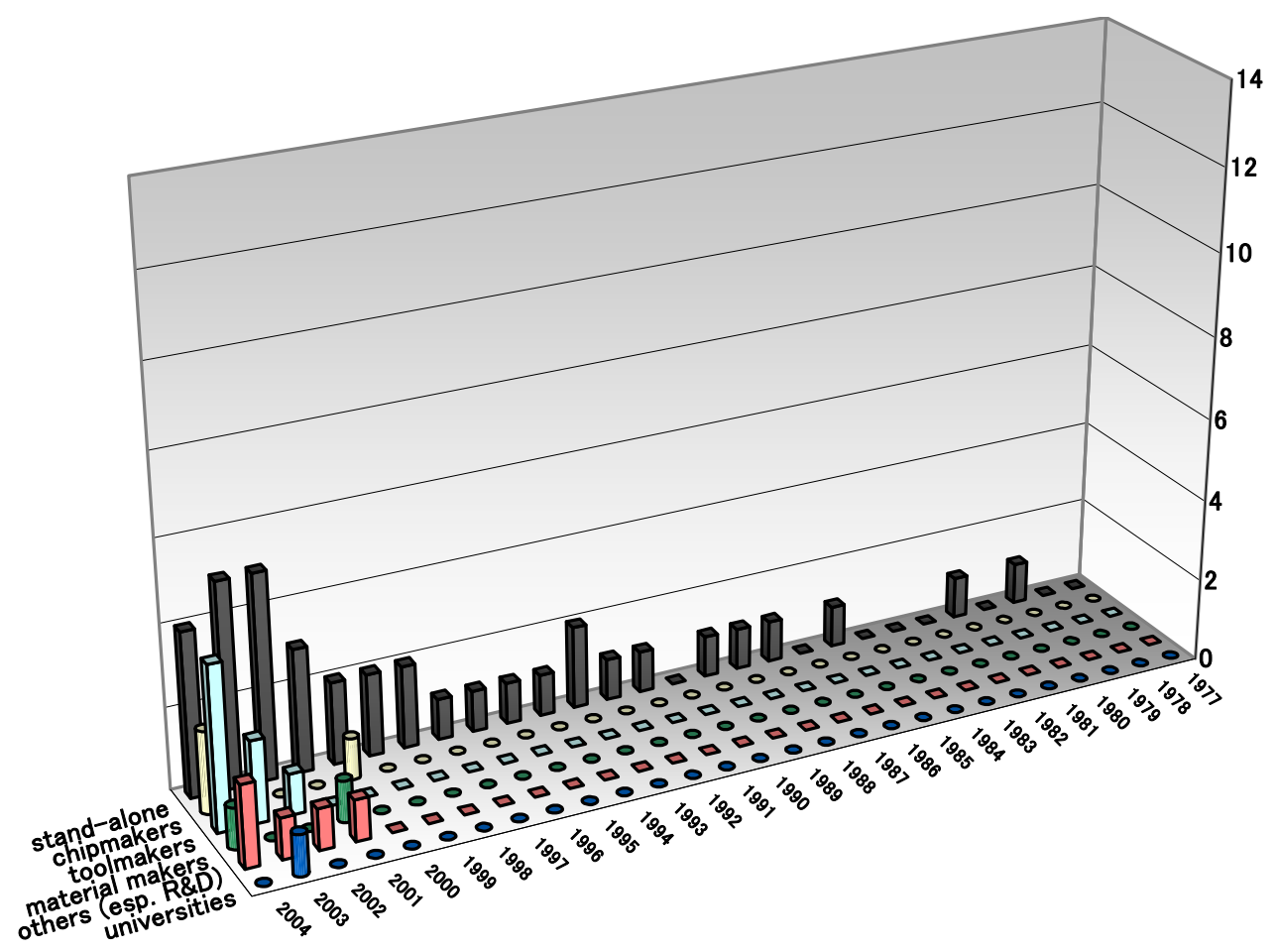

SPIE conferences can be very useful in getting valuable ideas from leading lithographers or scientists and receiving valuable comments from them, ${ }^{58}$ and ASML has been using this conference more effectively than either Nikon or Canon. This observation can be supported indirectly by data shown in Figures 6 through 8, which plot the number of papers presented at SPIE conferences by ASML (group of ASML, Philips and Zeiss), Nikon or Canon between 1977 and 2004. ${ }^{59}$ Because of the close relationship among ASML, Philips and Zeiss, we count papers submitted by these companies as ASML's stand-alone papers. The vertical axis in these figures represents the number of papers

\footnotetext{
${ }^{58}$ This point is explicitly emphasized by ASML's and Canon's technologists as well as by leading development lithographers in SONY.

${ }^{59}$ The trend does not change if ASML is counted as a single entity, not as part of its group.
} 
presented while the horizontal axes $(\mathrm{X}, \mathrm{Y})$ represent the year the conference was held and the type of papers presented: stand-alone, with chip manufacturers, with material manufacturers, with others (especially R\&D institutions), or with universities.

We assume that the larger the number of stand-alone papers, the lower each company's increasingly difficult for microlithography manufacturers to increase the speed of innovation without collaborating with various manufacturers or institutions. If the architecture embodied in microlithography tools is relatively more open and modular than the others during the development phase, it will be easier for outside scientists and engineers to understand the corresponding hardware and software structure deeply, making their improvisations with inside scientists and engineers easier.

According to Figure 6, ASML began to collaborate widely with chip, tool and material manufacturers in the mid 1990s, accelerating the pace of their collaboration in 1998. In contrast, although collaborations in Nikon and Canon tended to increase recently, the majority of their papers have been stand-alone (see Figure 7 and Figure 8). This tendency is particularly striking for Nikon (Figure 7). However, this tendency not to collaborate cannot be ascribed solely to Nikon or Canon, because Japanese chipmakers had not opened their development process technologies to tool manufacturers until recently. Thus, the recognition level of interim modularity may be much lower in Japanese chipmakers than in tool manufacturers.

Furthermore, it should be noted that ASML established an ASML Technology Development Center $^{60}$ in the United States in 1999 in order to extend its R\&D activities in imaging technology and process integration. According to ASML's leading technologist, ASML has been trying to collaborate closely with leading semiconductor-related manufacturers in finding specific solutions for these manufacturers. This center is also expected, as part of its R \&D, to work with outsiders effectively to substantiate various novel but undeveloped ideas provided by leading semiconductor-related manufacturers (especially chipmakers) in SPIE.

\footnotetext{
${ }^{60}$ This used to be called the U.S. Technology Development Center.
} 


\subsection{Collaborative Development Method of Embedded Control Software}

When the complexity of control software exceeds a certain threshold, the usefulness of interim modularity takes on prominence. Relationships between ASML and various Dutch universities or software venture companies exist for such situations. ASML has a long-established relationship with a group of Dutch universities in which TU/e (Technische Universiteit Eindhoven), located in the castle town of Philips (Eindhoven), constitutes the main strength. Such a relationship is evident from many of the master's and doctoral theses executed in collaboration with ASML at TU/e's engineering department. ${ }^{61}$ According to the annual report by the TU/e engineering department, ASML awards have been granted to students with excellent academic records every year. In addition, it should be noted that TU/e has been one of the top universities for software engineering in Europe. ${ }^{62}$

A more noteworthy fact is that ASML recently introduced a novel software architecture based on UML (Unified Modeling language) from a fairly early period for the development of innovative dual-stage microlithography called TWINSCAN for $300 \mathrm{~mm}$ wafers (Gevers, 2000). ${ }^{63}$ The use of UML allows one to identify the interdependencies of key microlithography modules under development at a fairly high level of abstraction. The most significant benefit of using UML is that it can provide power of panopticon for various kinds of engineers and scientists at a highly abstract level. The UML extended by ASML with TU/e can automatically connect to the advanced simulator (called

\footnotetext{
${ }^{61}$ The titles of some of these theses are "Improving throughput performance of Litho Cells at ASML: a simulation study with Arena" (2002), "Process dependency of level sensor: design of tools to investigate height process dependency in ASML PAS5500 and Twinscan Level Sensors" (2001), "Design verification of the Twinscan Control Software" (2000), "Influence of reticle handling on TWINSCAN throughput" (2000). For details, see http://library.tue.nl/catalog/Vubis.csp?OpacLanguage=eng.

${ }^{62}$ The information comes from a software engineering expert. Prof. Edsger W. Dijkstra (1930-2002), the world renowned proponent of structured programming, used to be a faculty member at TU/e.

${ }^{63}$ UML has recently become very popular in the world in relation to object-orientated programming (see D'Souza and Willis: 1998). Table 1 in the previous section illustrates how Twinscan took complexity to another abstraction level compared to previous models.
} 
$\chi$ model) developed by TU/e so that the optimum controllability of various parallel and/or sequential processing can be confirmed beforehand, even at a much lower abstract level (e.g., Albu, 2003).

Judging from the fact that the first commercialized TWINSCAN became available at the end of 2000, the control software development for TWINSCAN using UML might have started two to three years prior to that time. So, in developing the embedded control software, ASML started to enjoy the power of panopticon benefits derived by UML as early as around 1997 or 1998 . There is nothing to suggest that either Nikon or Canon has started to employ the combination of ULM plus the corresponding simulator in current models.

Another project, a Dutch national venture called the Tangram Project, was launched mainly by the initiative of the TNO microlithography division in March $2003 .{ }^{64}$ The main objective of this project is to collect all the wisdom of Dutch specialists in order to provide an innovative basic structure for the embedded-control software of ASML scanners that have evolved into extreme complexity. The project participants consist of TU/E, three other Dutch universities, TNO, Philips and software venture companies, as well as ASML. ${ }^{65}$ Figuratively speaking, the situation is tantamount to one in which the University of Tokyo, Tokyo Institute of Technology, Osaka University, the National Institute of Advanced Industrial Science and Technology (AIST), Toshiba, CSK and software TLOs ${ }^{66}$ get together to develop the embedded-control software for Nikon's state-of-the-art scanners. Unless the embedded software of Nikon's scanners were hierarchically visible at a glance with considerable certainty, such an improvisation could not be successfully done at all.

\section{Conclusion and Implications}

This paper examined how Japanese science-based industry has been responding to its rapidly

\footnotetext{
${ }^{64}$ The Ideals Project, a joint venture of ASML, TU/e and other universities, designed to replace built-in software for ASML scanners with object-orientated software also began in 2003. For details, see Onvlee et al., 2003.

${ }^{65}$ For further details, see http://www.embeddedsystem.nl/ .

${ }^{66}$ Technology Licensing Organizations.
} 
advancing complexity by focusing on the microlithography industry as a typical example. In this industry, Nikon and Canon were quite dominant until around the mid 1990s. ASML of the Netherlands, however, began to increase its competitive strength rapidly in the mid 1990s, and these three companies are currently engaged in a fierce dead-heat competition. ASML appears to have a slight lead in terms of speed of innovation, even in the state-of-the art lithography tools. The objective of this paper was to answer to the following questions: Why has the global market share in the microlithography market been reversed? What kinds of factors mainly influence such a reversal? How extensively are such factors generalizable to other kinds of science-based industries, beyond the microlithography industry? What kinds of additional measures are desirable for vertically integrated corporations like Nikon or Canon?

The analysis indicated that in response to the increasing demand for miniaturization in submicron order, due to Moore's law, a new technology called RET (Resolution Enhancement Technology) was created, which--together with DUV steppers--aroused the revolutionary wave in the mid 1990s. RET made it possible to print IC patterns in a photomask onto a silicon wafer at less than half the wavelength. Although the introduction of RET opened a new frontier for microlithography tools, at the same time manufacturers began to experience quite complex problems that they had not confronted previously. As the situation became more complicated, finding root causes that lead to imprecise printing accuracy became more and more difficult, so that it became necessary for microlithography manufacturers to collaborate with leading chipmakers and tool, photomask, material and/or EDA software manufacturers beyond their corporate boundaries. It was at about this period that ASML made great leaps ahead.

Unlike Nikon or Canon, ASML seems to be involved only in system design and final assembly while depending on outside institutions, like Philips, Zeiss, TNO and IMEC, for R\&D and key component assembly. Accordingly, at first glance, it is hard to understand how ASML could gain such high R\&D capabilities that surpass even Nikon's or Canon's. Our research has clarified this issue. 
ASML is, in fact, a huge industrial complex with Philips, Zeiss, IMEC and TNO intricately combined with ASML by various kinds of exclusive contracts. Moreover, the organizational form of such a complex is itself thoroughly contemporary, compared with the traditional vertically integrated forms of Nikon or Canon, in that the corporate boundaries are quite flexible and porous so as effectively to orchestrate dispersal of specialized knowledge and know-how over a wide range of professionals inside and outside the complex. In this complex, an Open Innovation à la Chesbrough (2003) can be implemented relatively easily. This point can be best exemplified by the fact that ASML has been benefiting from having exclusive access to IMEC, the world famous R\&D consortium, where ASML can have an effective place for resonance, through her $\beta$ tools, with a number of world-leading chip, tool and material manufacturers.

The second important difference between ASML and its Japanese counterparts is related to the modular architecture embodied in ASML's various microlithography tools. To be sure, tolerances of microlithography tools are much tighter than the tolerances for each key component and so the corresponding architecture must be extremely closed and integral, even for ASML's tools when seen as finally commercialized products. Such a closed and integral nature tends, however, to be a big stumbling block for extremely complex microlithography tools because establishing the relevant system architecture at the initial development phase becomes more and more difficult. In other words, the relevant architecture per se has to be sought beyond corporate boundaries even during the development processes. The necessity for such border transgression has been particularly high since the mid 1980s when RET, together with DUV steppers and scanners, became indispensable.

In finding such an effective architecture, ASML tends to behave more efficiently than Nikon or Canon. To do that, ASML pays more explicit attention to the importance of interim modularity. The concept of interim modularity was defined in this paper as the communication benefits induced by modular architecture during the trial-and-error development processes, no matter how incomplete such architecture may be. Extremely complex tools like microlithography require interim modularity 
effectively to orchestrate specialized knowledge and know-how dispersal over a wide range of professionals inside and outside of corporations. This paper illustrated, based on data describing ASML'S collaboration in SPIE and ASML's development methods for embedded control software, the fact that ASML is more effective in pursuing and responding to the importance of interim modularity than Nikon or Canon.

As stated at the beginning of this paper, waves of scientific and technological innovations are constantly bombarding various fields at astonishing rates. This trend is particularly prominent in the science-based industries, where, in order to harness information-processing capabilities of the right people in the right places, the full-scale organizational management becomes indispensable over a wide range of related areas. To achieve this communication an organization must pursue interim modularity, which can be effectively implemented only in the highly visualized organizations where both the rapidly changing circumstances and the appropriate knowledge are hierarchically visible at a glance and effectively shared by the people involved, with considerable certainty. It is here that various limits of organization have shown up in many Japanese firms, as well as in Nikon or Canon, primarily because discontinuously enhancing visibility tends inevitably to entail serious conflicts of interest at various hierarchical layers.

To be sure, one strength of the Japanese manufacturing industry has traditionally been its abundance of people with tacit specialized and integrated knowledge that spans a wide range of areas within each division or corporation. Those people are still relatively abundant, but the increasing complexity observed in science-based industries yields new problems that those people can no longer cope with effectively by only using their knowledge in stand-alone mode. This is mainly because the range of optimization has been rapidly expanding far beyond the traditional knowledge boundaries so that, without enhancing the compatibility of their tacit knowledge for networking, the scarcity itself could no longer be maintained as it was. Establishing such compatibility, however, is quite a difficult job because the new type of integrated knowledge must be newly accumulated at a higher abstract 
level. Moreover, making the tacit knowledge explicit tends to invoke serious conflicts of interest at various hierarchical layers. Many Japanese corporations that have an abundance of specialized and integrated knowledge below a desirable abstract level appear to be behind in setting up an efficient mechanism to create such a new abstraction level of integrated knowledge. This challenge appears to weaken even the competitiveness of such science-based industries as the microlithography industry.

\section{Appendix: Corporate Governance à la $\mathrm{ASML}^{67}$}

In Europe, and in particular in the Netherlands where ASML is based, attempts have been made to expand the degree of freedom for executive boards by "articles of association" to mitigate the enforceability of corporate law. Similar freedom began to be guaranteed in Japan in November 2001. These differences in corporate law might have induced a significantly different style of corporate governance between ASML and Nikon or Canon.

ASML Holding NV (Naamloze Vennootschap), which is the parent entity of ASML, could issue so-called classified stocks, such as Priority Stocks (PS) or Preference Stocks (PRS). Classified stockholders may be entitled to various types of voting rights, residual rights, dividends, and so forth. ASML's articles of association also stipulate that the Priority Stock Foundation (PSF) would be composed of three ASML outside board members and two ASML board members and could impose

\footnotetext{
${ }^{67}$ I owe much to Joost van Acht, who came to Hitotsubashi University as a master's student of research in an exchange program from Erasmus University in the Netherlands. I wish to take this opportunity to acknowledge his contribution and thank him. Much of the contents of this section were based on information taken from the ASML U.S. SEC documents (February 18, 2003). The author wishes to take this opportunity to acknowledge his contribution and thank him.
} 
considerable restrictions over the voting power of general shareholders' meetings. Furthermore, a Preference Stock Foundation (PRSF) could be formed at any time, as the occasion demands. It would be composed of three members from the Dutch business and university sectors and ASML's outside board chairperson. The PRFS could serve as a significant safeguard for board members if a third-party takeover is attempted, because the board members are legally authorized to issue PRS shares equal to the number of ordinary shares outstanding and to give PRS and PRSF a priority option to purchase shares at a low price (book value), provided both the outside board meeting and PSF approve such action.

Thus, ASML board members are assured of more operational and organizational freedom than Nikon or Canon board members. Furthermore, they have the privilege of having managerial prerogatives for the aforementioned exclusiveness that are necessary for science-based industries. Of course, to discourage a self-approving attitude of board members, the outside boards are granted a powerful right for monitoring them. This function virtually does not exist in Japan. 


\section{References}

- Albu, Tim F., “AML - A visual programming language for ASM Lithography,” Aug. 22, 2003 (wwwooti.win.tue.nl/projects/2002/ results/Albu.20030822.pdf)

- Baldwin, Carlis Y. and Kim B. Clark (2000), The Design Rules: The Power of Modularity Vol. 1, MIT Press.

- Bruntink, Magiel, Arie van Deursen, Tourw'e Tom, van Engelen Remco (2004), “An Evaluation of Clone Detection Techniques for Identifying Crosscutting Concerns," in IEEE International Conference on Software Maintenance (ICSM'04), Chicago, Illinois, pp. 200-209

- Chandler, Alfred D., Jr. Strategy and Structure: Chapters in the History of the American Industrial Enterprise, MIT Press, 1962, Cambridge, Massachusetts

- Chesbrough, Henry (2003), Open Innovation: The New Imperative for Creating and Profiting From Technology, Harvard Business School Press, Boston, Massachusetts

- Csete, Marie E. and John C. Doyle (2002), "Reverse Engineering of Biological Complexity,” in SCIENCE, 1 March, VOL 295, pp.1664-1669.

- D'Souza, Desmond Francis and Alan Cameron Wills (1998), Objects, Components, and Framework with UML: The Catalysis Approach, Addison-Wesley, Boston, San Francisco, New York, Toronto, Montreal, London, Munich, Paris, Madrid, Capetown, Sydney, Tokyo, Singapore, Mexico City.

- Dunn, Doug J., (2002), Presidential Address at the ASML Bits \& Chips Conference held on April $16^{\text {th }}$ in Veldhoven, The Netherlands.

- Fujimura, Shuzo (2000), Handotai Rikkoku Futatabi (Nation of Semiconductor Once More), Nikkan Kogyo Shinbun-sha

- Fine, Charles H. (1998), Clockspeed: Winning Industry Control in the Age of Temporary Advantage, Perseus Books 
- Fujimoto, Takahiro (2001), "Architecture no Sangyo-ron (Theory of Industry in view of Architecture," in Business Architecture: Seihin Soshiki Process no Senryakuteki Sekkei (Business Architecture: Strategic Design of Products, Organizations, Processes), Yuhikaku.

- George, Richard, (2002), "Marketing and Development of High Tech Product Families: Based on ASML Semiconductor Business Experience," (from http://sepc.twi.tudelft.nl/ toet/onderwijs/ in4073/slides/ASML/)

- Gevers, Joost J.A. (2000), Design verification of the TWINSCAN Control Software, Eindhoven : Technische Universiteit Eindhoven, 2000.

- Goto, Akira and Hiroyuki Odagiri (2003), Nihon-no Sangyo System (3): Science-gata Sangyo (Japanese Industry System (3): Science-based Industry), NTT Shuppan

- Henderson, Rebecca M. and Kim B. Clark (1990), “Architectural Innovation: The Reconfiguration of Existing Product Technologies and the Failure of Established Firms," Administrative Science Quarterly, vol.35, no1, pp.9-30.

- Helper, Susan (2000), "Economists and Field Research: You Can Observe a Lot Just by Watching,” American-Economic-Review; 90(2), May 2000, pages 228-32.

- Hirota, Yoshito (2002), "Handotai Roko-sochi no Kaihatsu (Development of Microlithography)," in Sengo Nihon no Gijyutsu Keisei: Moho ka Sozo ka (Technology Formation in Post-war Japan: Imitation or Creation), Nihon Hyoron-sha

- Johnson, Thomas H., and Anders Broms (2000), Profit Beyond Measure: Extraordinary Results Through Attention to Work and People, Free Press.

- Kozu, Hideaki and Hiroyuki Chuma (2004), "Wagakuni Handotai Sangyo Fuchin no Kozu: NEC no Jirei ni motozuku Fukuzatusei Zodai to Soshiki Genkai (Rise and Fall of Japanese Semiconductor Industry: Increasing Complexity and Limits of Organization observed in NEC," mimeo. 
- Lamoreaux, Naomi R., Daniel M. G. Raff, and Peter Temin. (2002), "Beyond Markets and Hierarchies: Toward a New Synthesis of American Business History,” Working Paper 9029, National Bureau of Economic Research, July.

- Langlois, Richard N. (2003), “The Vanishing Hand: the Changing Dynamics of Industrial Capitalism," Industrial and Corporate Change 12(2): 351-385 (2003).

- Levinson, Harry J. (2001), Principles of Lithography, SPIE Press, Bellingham, Washington, USA.

- Liebmann, Lars W. , Scott M. Mansfield, Alfred K. Wong, Mark A. Lavin, William C. Leipold, and Timothy G. Dunham (2001), "TCAD development for lithography resolution enhancement," IBM Journal of Research and Development, Volume 45, Number 5, http://www.research. ibm.com/journal/rd/455/liebmann.html

- Rick van Lierop and Joost Zonneveld, "ASML-AT:Turbo Scanner Software Architecture “XOOTIC Magazine, March 2000, vol.7, no.3, pp.12-18. www.win.tue.nl/xootic/magazine/mar2000/vanlierop.pdf

- Mori Ichiro and Tatsuhiko Higashiki (2004), "Sentan Lithography Gijyutsu no Kadai to Kakushin (Problems and Innovation in the State-Of-The-Art Microlithography)," http://www.toshiba.co.jp /tech /review/2004/08/59_08pdf/a03.pdf

- Onvlee, Hans, van Engelen Remco, and Beenker Frans (2003), Summary Project plan Ideals project, (http://www.embeddedsystems.nl/PRO1/general/show_document_general.asp?document $\mathrm{id}=618)$

- Roberts, John (2004), The Modern Firm: Organizational Design for Performance and Growth (Clarendon Lectures in Management Studies), Oxford University Press, 2004

- Roest, P. and P. Schuurmans (1997). "Strategic sourcing als basis voor innovatie: ASM Lithography," Nijenrode Management Review, Vol. 2, pp.14-23. 
- Schellenberg, Franklin M. (2004), "Resolution Enhancement Technology: The Past, The Present, and Extent ions for the Future," Optical Lithography XVII, ed. by B.W. Smith, Proceedings of SPIE, vol. 5377, 2004, pp.1-20.

- Suzuki, Akiyoshi (2003), "Hikari Lithography Gijyutsu (Technology in Photolithography)," in Hajimete-no Handotai Lithography Gijyutsu (Introduction to Microlithography), ed. by Shinji Okazaki, Akiyoshi Suzuki, and Takumi Ueno, Chapter 2, Kogyo Chosa-kai

- Tarui, Yasuo and Semiconductor Equipment Association in Japan (SEAJ) (1991), Handotai Rikkoku Nihon: Dokuso-teki na Sochi ga Kizukiageta Kiroku (Japan as a Nation of Semiconductor Nation), Nikkan Kogyo Shinbun-sha

- Thin Film Manufacturing (2002), "Nikon vs. ASML Part I: Analyzing the ITC complaint," and "Nikon vs. ASML and Part II: The case in Federal District Court," (http://www.thinfilmmfg.com/ subscribers/Subscriber02/Nikon16Jan02.htm\#light) and (http://www.thinfilmmfg.com/subscribers/Subscriber02/Nikon23Jan02.htm)

- VLSI (1992), Microlithography and Mask Making, (http://www.vlsiresearch.com)

- Wittekoek, S. (1980), “Step and Repeat Wage Imaging," in Semiconductor Microlithography V ed. by Jim Deay, Proceedings of the Society of Photo-Optical Instruments Engineers, vol. 221, pp.2-8.

- Wolf, Stanley (2004), Microchip Manufacturing, Lattice Press, Sunset Beach, California.

- Zuboff, Shoshana (1988), In the Age of the Smart Machine: The Future of Work and Power, Basic Books. 